\title{
A Simplified Sliding Mode Controlled Electronic Differential for an Electric Vehicle with Two Independent Wheel Drives
}

\author{
Azeddine Draou \\ Department of Electrical Engineering, University of Hail, Hail, Saudi Arabia \\ Email: adraou@yahoo.com
}

Received May 19, 2013; revised June 19, 2013; accepted June 26, 2013

Copyright (C) 2013 Azeddine Draou. This is an open access article distributed under the Creative Commons Attribution License, which permits unrestricted use, distribution, and reproduction in any medium, provided the original work is properly cited.

\begin{abstract}
This paper presents a simple sliding mode control strategy used for an electronic differential system for electric vehicle with two independent wheel drives. When a vehicle drives along a curved road lane, the speed of the inner wheel has to be different from that of the outer wheel in order to prevent the vehicle from vibrating and travelling an unsteady path. Because each wheel of this electrical vehicle has independent driving force, an electrical differential system is required to replace a gear differential system. However, it is difficult to analyse the nonlinear behaviour of the differential system in relation to the speed and steering angle, as well as vehicle structure. The proposed propulsion system consists of two permanent magnet synchronous machines that ensure the drive of the two back driving wheels. The proposed control structure called independent machines for speed control allows the achievement of an electronic differential which ensures the control of the vehicle behaviour on the road. It also allows to control, independently, every driving wheel to turn at different speeds in any curve. Analysis and simulation results of the proposed system are presented in this paper.
\end{abstract}

Keywords: Electric Vehicle; Sliding Mode Control; Electronic Differential; Permanent Magnet Synchronous Motor; Multimachine Multiconverter System

\section{Introduction}

Electric vehicle with in-wheel motors has remarkable advantage in the quick generation of precise torque on each driving wheel $[1,2]$. Some applications in the field of electrical drives require the use of several electric machines and as many static converters that have an important place among the electromechanic systems. These systems are called multi-converter multi-machine systems (MMS) [3]. A formalism has been developed in order to study systems composed of several electrical machines and/or power converters. It points out three energetic couplings inside the electromechanical conversion chains: electrical, magnetic and mechanical coupling. Adaptive rules based on the inversion principle are suggested for the control of such systems. Energetic repartition criteria have to be defined to solve the coupling problems [4]. They are recognized through the existence of the coupling system type either of an electric nature, a magnetic and/or mechanical one used in several electric machines propelling the vehicle. In such a system, we model the coupling by using appropriate structures in- cluding independent control, slave-master, by imposing criteria of energetic distribution in order to obtain a single machine or a single converter system. One of these control structures can be applied to the control of electric vehicle driving wheels.

\section{Proposed Traction System}

The classical configuration of the electric vehicle traction system is represented in Figure 1 [5].
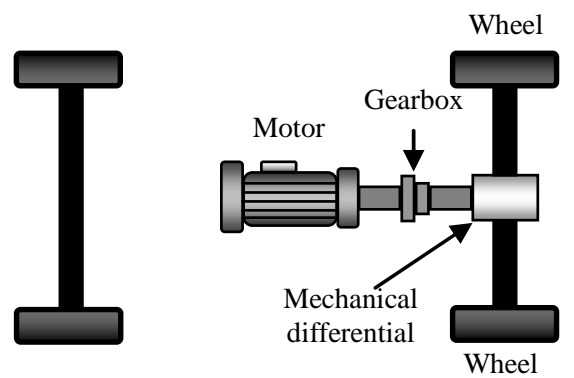

Figure 1. Conventional Vehicle structure with one central motor. 
Figure 2 shows the structure of the electric vehicle, the two rear wheels are driven by two traction motors through reduction gears and drive shafts [6]. This figure represents the implemented vehicle configuration using two permanent magnet synchronous motors for two independent wheels.

The multi-machine systems are characterized by the coupling of different electromechanical conversion systems. The system represented by Figure $\mathbf{2}$ is characterised by only one coupling which is illustrated by Figure 3. In order to design the electronic differential, the control structure "independent machines" is applied to the propulsion system of two driving wheels, by a speed control, as shown in Figure 4.

\section{Independent Machine Control}

This structure is composed of two machines controlled independently as two single machine structures. For every machine we can impose different speed reference $\left(\Omega_{r \text { rref }} \neq \Omega_{\text {rLref }}\right)$ by using two static converters. These machines are uncoupled through the control structure and reject all disturbances like single machine control. The

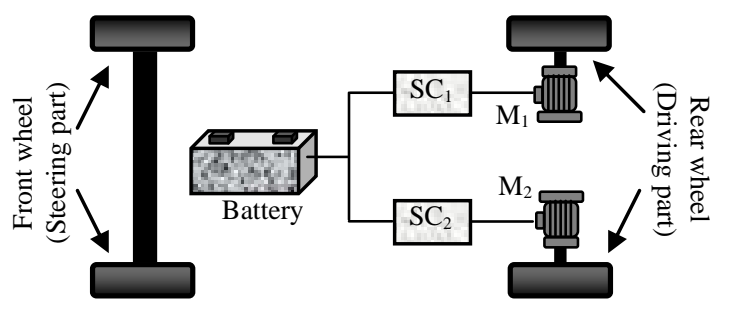

Figure 2. Vehicle structure with two independent rear wheel drives.

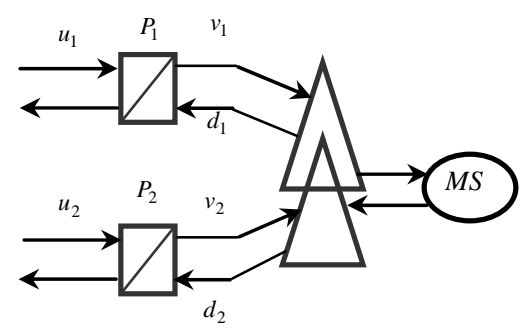

Figure 3. Studied topology.

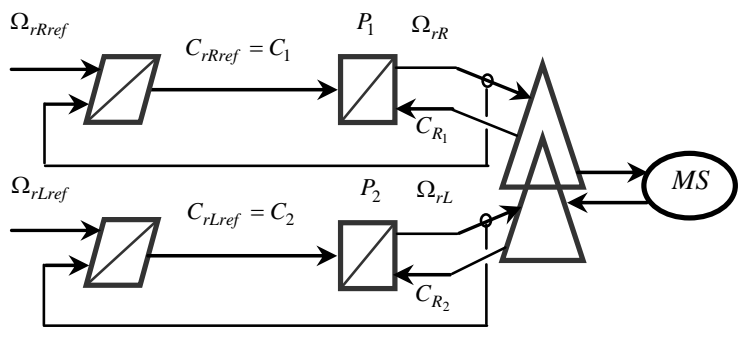

Figure 4. Independent machine structure. principle of this control is illustrated by Figure 4.

An energetic macroscopic representation (EMR) of the propulsion system was proposed to obtain a global view of an electronic differential as shown in Figure 5.

This investigation proposes the control of the driving wheels speeds $\Omega_{\omega_{-} R}$ and $\Omega_{\omega_{-} L}$ by the "independents machines" control structure. This structure allows to impose two speed references $\Omega_{\omega_{-} R} \neq \Omega_{\omega_{-} L}$ (i.e. in a curve), the applied torque on each wheel is different $T_{\text {gear } \_R} \neq T_{\text {gear } \_}$, the two wheels control system does not receive the same torque reference. Thus, it is not possible to impose the same speed reference.

The electronic differential system uses the vehicle velocity and steering angle as input parameters and calculates the required inner and outer wheels speeds where the two rear wheels are controlled independently by two PMS motors. The inputs of the reference block are the vehicle speed, and the steering angle, whereas the outputs are the required rotation speeds of the inner and outer wheels, referred to as reference speeds. According to the steering angle direction (left or right), the rotational speed of the inner wheel and outer wheel is allocated to the rotation speed of left wheel and right appropriately.

The power structure is composed of two permanent magnet synchronous motors which are supplied by two three-phase inverters and driving the two rear wheels of a vehicle through gearboxes as shown in Figure 6.

\section{Vector Control}

Figure 7 illustrates the vector control scheme of a permanent magnet synchronous motor. It represents the speed control system with $i_{d}$ and $i_{q}$ current controls.

In order to simplify the control algorithm and improve the control loop robustness, we propose to use the sliding mode control strategy.

The PMSM equations are given as follows:

$$
\begin{gathered}
\frac{\mathrm{d} i_{d}}{\mathrm{~d} t}=f_{1}+\frac{1}{L_{d}} v_{d} \\
\frac{\mathrm{d} i_{q}}{\mathrm{~d} t}=f_{2}+\frac{1}{L_{q}} v_{q} \\
\frac{\mathrm{d} \omega_{m}}{\mathrm{~d} t}=f_{3}
\end{gathered}
$$

where

$$
\begin{gathered}
f_{1}=-\frac{R_{s}}{L_{d}} i_{d}+\frac{L_{q}}{L_{d}} \omega_{m} i_{q} \\
f_{2}=-\frac{R_{s}}{L_{q}} i_{q}-\frac{L_{d}}{L_{q}} \omega_{m} i_{d}-\frac{\Phi_{f}}{L_{q}} \omega_{m} \\
f_{3}=\frac{p^{2}}{J}\left[\left(L_{d}-L_{q}\right) i_{d}+\Phi_{f}\right] i_{q}-\frac{p}{J} T_{r}-\frac{f}{J} \omega_{m}
\end{gathered}
$$




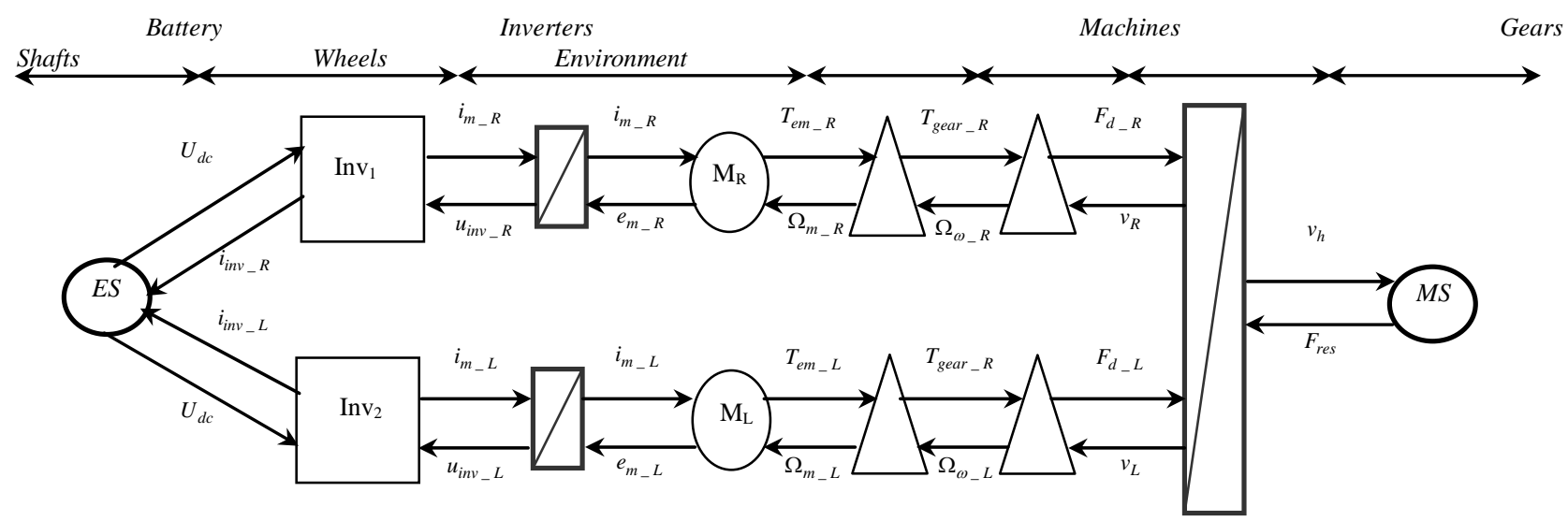

Figure 5. EMR of the electronic differential system.

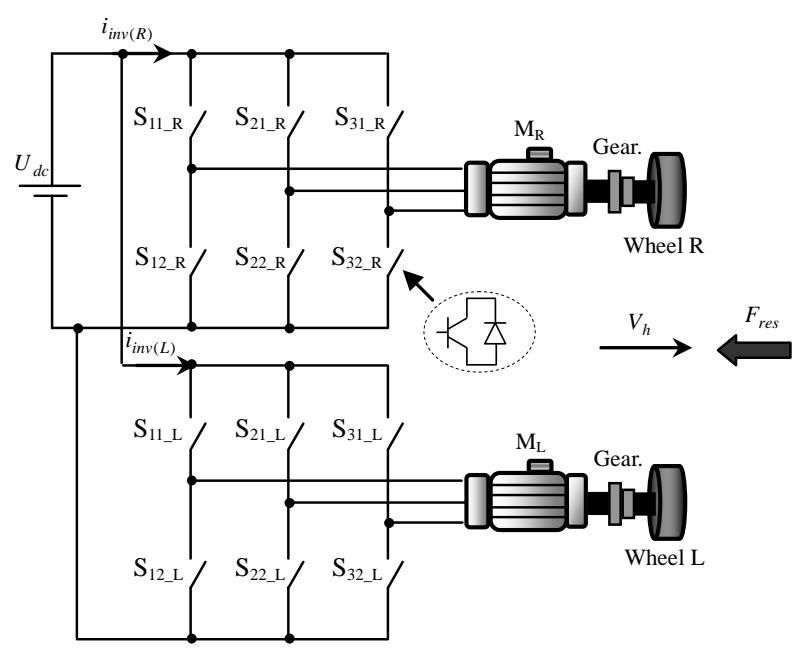

Figure 6. Components of the proposed system.

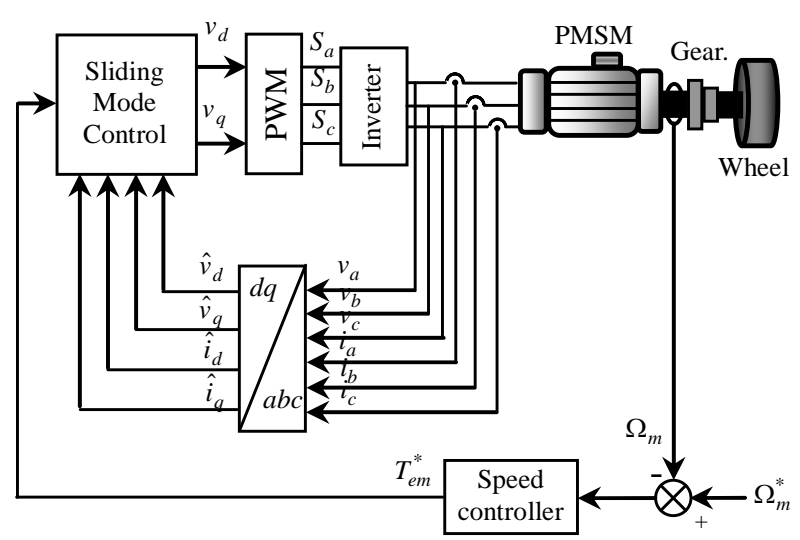

Figure 7. Block-diagram of an electric drive system for PMS motors.

- Speed and current sliding mode controller

Using the non-linear PMSM model of "Equation (1)", it is possible to design both a speed and a current sliding mode controller $[7,8]$. Let us define the sliding surface

$$
\begin{gathered}
S_{c 1}=S_{c 1}\left(\omega_{m}\right)=\lambda_{\omega}\left(\omega_{m}^{*}-\omega_{m}\right)+\frac{\mathrm{d}}{\mathrm{d} t}\left(\omega_{m}^{*}-\omega_{m}\right) \\
S_{c 2}=S_{c 2}\left(i_{d}\right)=\left(i_{d}^{*}-i_{d}\right)
\end{gathered}
$$

where $\lambda_{\omega} \succ 0, \omega_{m}^{*}$ and $i_{d}^{*}$, are the speed reference and the reference stator current, respectively.

To determine the control law which is expected to steer the sliding function (3) to zero in finite time, one has to consider the dynamics of $S_{c}=\left[S_{c 1} S_{c 2}\right]^{T}$, described by:

$$
\dot{S}_{c}=A+B V_{s}
$$

where

$$
\begin{gathered}
A=\left[\begin{array}{c}
\ddot{\omega}_{m}^{*}+\lambda_{\omega} \dot{\omega}_{m}^{*}-a f_{1}-b f_{2}-c f_{3} \\
i_{d}^{*}-f_{1}
\end{array}\right] \\
B=\left[\begin{array}{cc}
-\frac{b}{L_{q}} & -\frac{a}{L_{d}} \\
0 & -\frac{1}{L_{d}}
\end{array}\right] \\
a=\frac{p^{2}}{J}\left(L_{d}-L_{q}\right) i_{q} ; b=\frac{p^{2}}{J}\left[\left(L_{d}-L_{q}\right) i_{d}+\Phi_{f}\right] ; \\
c=\lambda_{\omega}-\frac{f}{J}
\end{gathered}
$$

In the Lyaponov method of stability it is used to ensure that $S_{c}$ is attractive and invariant, the following condition has to be satisfied

$$
S_{c}^{T} \cdot \dot{S}_{c} \prec 0
$$

So, it is possible to choose the switching control law for stator voltages as follows:

$$
\left[\begin{array}{l}
v_{q} \\
v_{d}
\end{array}\right]=-B^{-1} F-B^{-1}\left[\begin{array}{cc}
K_{\omega} & 0 \\
0 & K_{i_{d}}
\end{array}\right]\left[\begin{array}{l}
\operatorname{sign}\left(S_{c 1}\right) \\
\operatorname{sign}\left(S_{c 2}\right)
\end{array}\right]
$$


where $K_{\omega} \succ 0, K_{i_{d}} \succ 0$

The sliding mode causes drastic changes of the control variable introducing high frequency disturbances. To reduce the chattering phenomenon, a saturation function $\operatorname{sat}\left(S_{c}\right)$ instead of the switching one $\operatorname{sign}\left(S_{c}\right)$ has been introduced:

$$
\operatorname{sat}\left(S_{c i}\right)= \begin{cases}\frac{S_{c i}}{\delta_{i}} & \text { if }\left|\left(S_{c i}\right)\right| \leq \delta_{i} \\ \operatorname{sign}\left(S_{c i}\right) & \text { if }\left|\left(S_{c i}\right)\right| \succ \delta_{i}\end{cases}
$$

where $\delta_{i} \succ 0$ for $i=1,2$ with $\delta_{1}=\delta_{\omega}$ and $\delta_{2}=\delta_{i_{d}}$

\section{Simulation Results}

To investigate the vehicle behavior for steering maneuvers in the transient and steady state during its movement on a curved road a series of tests have been performed through simulation using Matlab/Simulink environment. The system was subjected to a speed level change of 30 $\mathrm{km} / \mathrm{h}$ or $8.32 \mathrm{~m} / \mathrm{s}$. The vehicle starts from standstill until reaching the speed of reference as shown in Figure 8(a). At this stage of operation, three turns are imposed on the vehicle, the first turn towards the left (at $t=22 \mathrm{~s}$ ), the second one towards the right (at $\mathrm{t}=36 \mathrm{~s}$ ) and the last one towards the left (at $t=68 \mathrm{~s}$ ). Figure 8 (b) shows the curves of the road, a positive curve corresponds to a turn on the right.

This figure presents the steering angle whose maximum value is of $\left(7^{\circ}\right)$. The vehicle turns towards the left at the instant of $t=22 \mathrm{~s}$ for $10 \mathrm{~s}$ with a speed of $30 \mathrm{~km} / \mathrm{h}$.

The driver gives a steering angle which starts by being a steering angle of the direct wheels (nose gear wheels). The electronic differential reacts immediately on the two motors, by lowering the speed of the left driving wheel

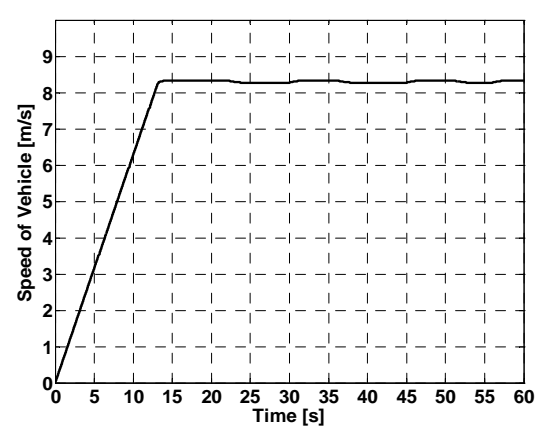

(a)

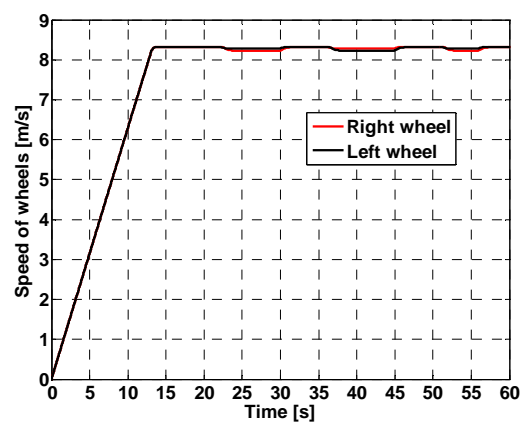

(d)

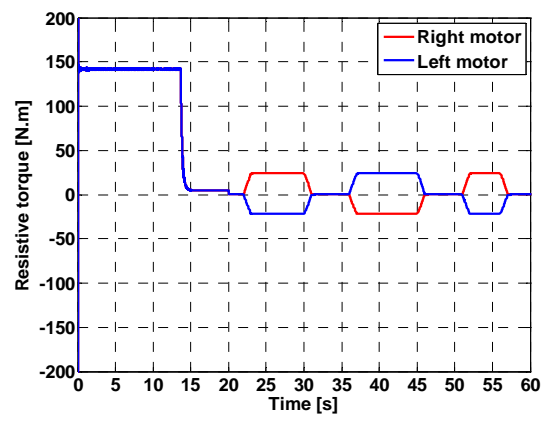

(g)

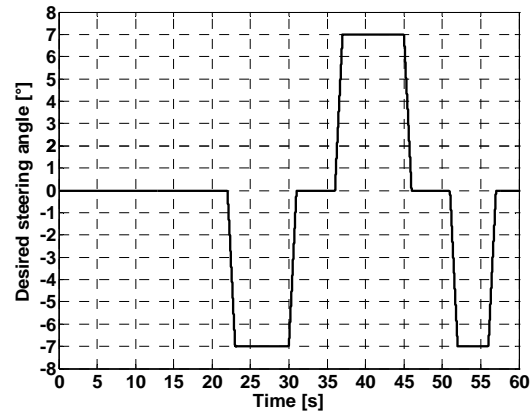

(b)

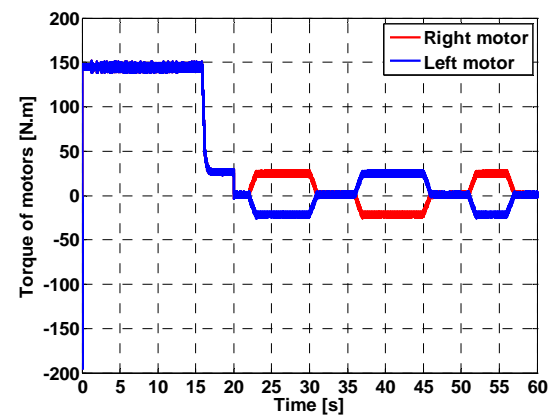

(e)

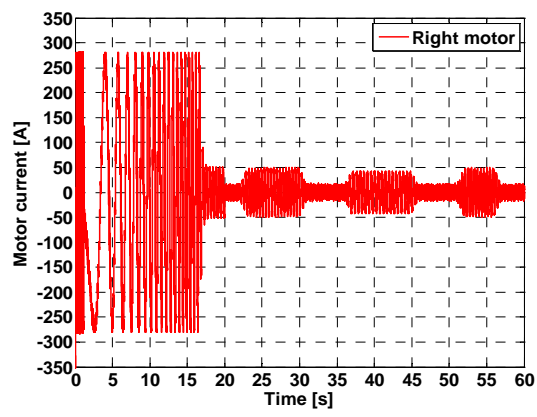

(h)

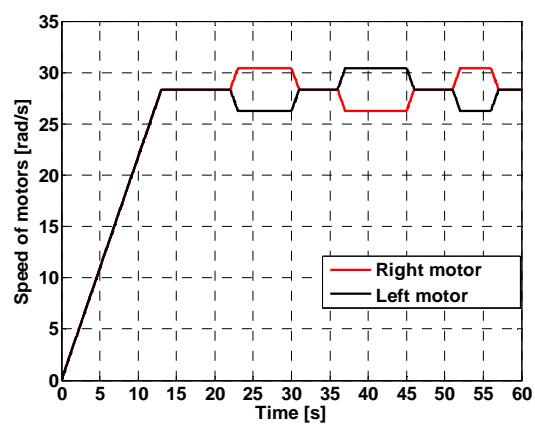

(c)

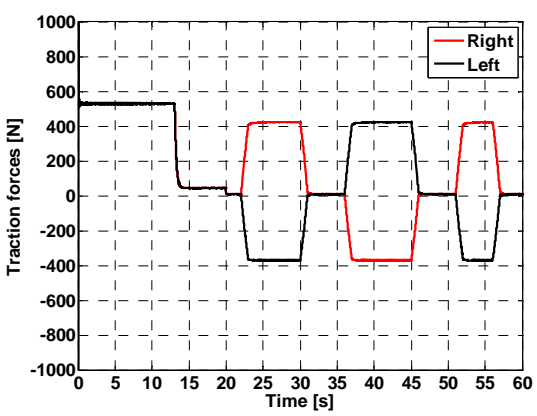

(f)

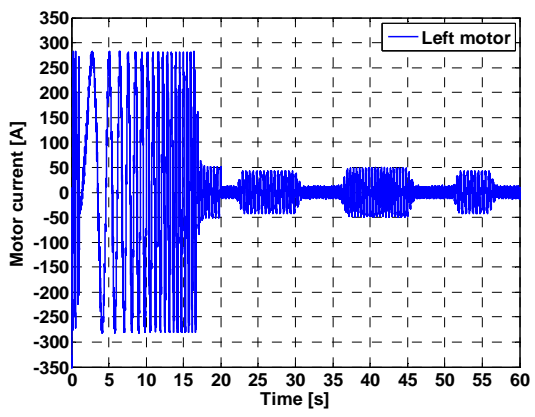

(i)

Figure 8. Transient responses of the vehicle during a curved road. 
(associated to the motor $M_{L}$ ) which is inside the turn, and the opposite to that motor which is located outside the turn, as shown in Figure 8(c). At this time, the speeds of the motors change values, this change will be reflected on the electric and mechanical quantities.

When the speed of the left wheel decreases according to its new reference, the torque tends to change its sign following the abrupt step change of the speed. The motor runs in the braking mode by developing a negative torque which can be exploited for a return back of energy towards the source.

The motors develop opposite torques as shown in Figure 8(e), one is cumulative to accelerate the wheel from outside and the other differential to decelerate the wheel which is inside the turn.

Figure 8(d) illustrates the linear velocities of the driving wheels. As soon as the speed of the left wheel is stabilized, the torque returns to the value of the corresponding resistive torque as shown in Figure 8(g). At the exit of the first turn at $t=31 \mathrm{~s}$, the driver gives the opposite angle of steering of the direct wheels and the differential acts of the same manner to make the speed difference equal to zero.

During the turns, the driving wheels go through different ways, they turn in the same direction at different speeds. These speeds are illustrated by Figure 8(c). When the speed of the right wheel (R) increases, the motor torque, associated with this wheel, increases and tends to catch up with the speed increase.

In Figure 8(f), we illustrate the forces of traction generated by the motors. We notice at first stage, strong forces of traction provided by the motors to make the vehicle move at starting. This seems obvious, because these forces must overcome the resistive forces to the advance of the vehicle. We can also notice a divergence between the forces of traction during the passage in the turns.

Indeed, the motors, which are inside the curve of turn, produce forces of traction lower than those of the motors which are outside the curve. Similarly for the resistive torques imposed on the motors, as shown in Figure 8(g).

The phase currents' changes of the motors (M1 and M3) are illustrated in Figures 8(h) and (i).

\section{Conclusion}

In the field of electric drives with variable speed, the application of an electric vehicle controlled by an electronic differential is presented in this paper. This paper proposes an "independent machine" control structure ap- plied to a propulsion system by a speed control. The results obtained by simulation show that this structure allows the design and implementation of an electronic differential and ensures good dynamic and static performances. The paper shows that the electronic differenttial controls the driving wheels speeds with high accuracy either in flat roads or curved ones. The disturbances do not affect the performances of the driving motors.

\section{Acknowledgements}

The author would like to express his deep gratitude to the University of Hail in Saudi Arabia for the continuous moral support and encouragement to research.

\section{REFERENCES}

[1] Y. Hori, "Future Vehicles Driver by Electricity and Control Research on Four Wheel Motored-UOT Electric March II,” IEEE Transactions on Industrial Electronics, Vol. 51, No. 5, 2004, pp. 954-962. doi:10.1109/TIE.2004.834944

[2] F. Tahami, R. Kazami and S. Farhanghi, “A Novel Driver Assists Stability System for All-Wheel Driver Electric Vehicles,” IEEE Transactions on Vehicular Technology, Vol. 52, No. 3, 2003, pp. 683-692. doi:10.1109/TVT.2003.811087

[3] A. Bouscaylor, B. Davat, B. de Fornel and B. François, "Multimachine Multiconverter System: Application for Electromechanical Drives,” European Physic JournalApplied Physics, Vol. 10, No. 2, 2000, pp. 131-147.

[4] A. Bouscaylor, B. Davat, B. de Fornel and B. François, "Multimachine Multiconverter System for Drives: Analysis of Coupling by a Global Modeling," Proceedings of IEEE-IAS, 2000, pp. 1474-1481. doi:10.1109/IAS.2000.882078

[5] C. C. Chan and K.T. Chan, "An Overview of Power Electronics in Electrics Vehicles,” IEEE, Vol. 44, No. 1, 1997, pp. 3-13. doi:10.1109/41.557493

[6] Y. Hori, Y. Toyoda and Y. Tsuruoka, "Traction Control of Electric Vehicule Based on the Estimation of Road Surface Condition. Basic Experimental Results Using the Test EV UOT Electric March,” IEEE Transactions on Industry Applications, Vol. 34, No. 5, 1998, pp. 1131-1138. doi:10.1109/28.720454

[7] V. I. Utkin, "Sliding Mode Control Design Principles and Applications to Electric Drives," IEEE Transactions on Industry Electron, Vol. 40, 1993, pp. 23-36. doi:10.1109/41.184818

[8] S.-I. Sakai and Y. Hori, “Advantage of Electric Motor for Antiskid Control of Electric Vehicle,” EPE Journal, Vol. 11, No. 4, 2001, pp. 26-32. 


\section{Abbreviations}

DFOC: Direct Field Oriented Control

EC: Electrical Coupling

EM: Electrical Machine

EMR: Energetic Macroscopic Representation

ES: Electrical Source

EV: Electric Vehicle

MMS: Multi-machine Multi-converter System

MS: Mechanical Source

PMSM: Permanent Magnet Synchronous Machine

PWM: Pulse with Modulation

\section{Nomenclature}

$L_{d}, L_{q}: d$ and $q$ axis inductance

$i_{d}, i_{q}: d$ and $q$ axis currents

$v_{d}, v_{q}: d$ and $q$ axis voltage

$R_{s}$ : Resistance

$p$ : Pole pairs

$\theta$ : Electric position
$\Phi_{f}$ : Permanent magnet flux

$J$ : Rotor inertia

$J_{v}$ : Vehicle inertia

$C_{e m}$ : Electromgnetic torque

$C_{r}$ : Load torque

$M$ : Vehicle mass

$R_{r}$ : Wheel raduis

$N_{\text {red }}$ : Report of speed gear

$\eta$ : Transmission efficiency

$l_{w}$ : Distance between two wheels and axes

$d_{w}$ : Distance between the back and the front wheel

$\rho:$ Air density

$S$ : Front area of vehicle

$C_{x}$ : Aerodynamic coefficient

$g$ : Acceleration of gravity

$f_{r}$ : Friction coefficient

$\alpha$ : Angle of the slope

$v_{h}$ : Linear speed of vehicle

$U_{d c}$ : Battery voltage 